\title{
Optimization of Long Distance Natural Gas Pipeline Design Proposals Based on Multi-objective AHM Method
}

\author{
DONG Feng-juan \\ College of Petroleum Engineering \\ Xi'an Petroleum University \\ Xi'an, China \\ dfj_1222@126.com
}

\author{
LU Xue-fei \\ College of Science \\ $\mathrm{X}$ i'an Petroleum University \\ Xi'an, China \\ luxuefei@xsyu.edu.cn
}

\begin{abstract}
AHM, and nine parameters which included diameter, delivery pressure, pressure ratio of the first station, pressure ratios of intermediate stations, number of stations, investment costs of pipeline ,investment costs of stations, investment costs of operation ,equivalent cost, have been selected to evaluate design projects of the long distance natural gas pipeline. The results indicate that attribute AHM matches other methods well. The calculation result of the example indicates that AHM method can get a good assessment result for the multifactor and multi-hierarchy complicated problems. The study provides a new method and technique for designers to select the technical feasible and economic reasonable design case, which has some theoretical and practical value.
\end{abstract}

Keywords-Natural gas pipeline; AHM method; design proposals; comprehensive assessment

\section{INTRODUCTION}

With the bulk mining of natural gas source globally, the construction of pipelines have been the important fundamental facilities and the mark of modern cities. It is particularly important to optimize national energy structure, improve the environment, and improve people's quality of life. Meanwhile, natural gas pipeline construction has many characteristics such as high investment, high technology, high risk, also natural gas is flammable, explosive in the process of transportation, once pipeline leakage, especially the main long pipeline accident, it will bring serious harm and loss to the country and people; Besides long natural gas pipeline construction has the characteristics of the big investment and wide influence. Therefore, making the gas pipelines design scheme is crucial, we must demonstrate the different design schemes fully in the aspects of technology and engineering. Since the 1990 s, from the different point of views to carrying on the analysis, using different evaluation system, from qualitative to quantitative (such as scheme comparison method, analytic hierarchy process, fuzzy analytic hierarchy process (AHP) and grey system method, fuzzy matter-element method, fuzzy decision, entropy weight coefficient method, etc.) ${ }^{[1-8]}$, all of them can identify optimal design scheme the same with evaluation standard consistent. But these qualitative and quantitative evaluation methods all involve the determining factors and weight problems, besides the use of evaluation method in the determination of weight in a certain extent are exist or not be able to avoid subjectivity, or Computational complexity, large amounts of calculation and so on, these have become the focus in today's scholars' eyes. Therefore, in order to make long natural gas pipeline design scheme of comprehensive evaluation result more scientific more credible, seeking a simple calculation and easy decision are very important. This paper taking a long natural gas pipeline design as an example, using the method of AHM to evaluate natural gas long-distance pipeline design scheme in the round gets a good result, which provides certain theoretical basis to ensure long natural gas pipeline construction operation, working and management benefit maximization effectively

\section{THE STEPS OF DETERMINING THE WEIGHTS WITH AHM METHOD ${ }^{[9-14]}$}

\section{A. The establishment of the evaluation system}

Through a comprehensive analysis of relationship and affiliation between 9 parameters: diameter, delivery pressure, pressure ratio of the first station, pressure ratios of intermediate stations, number of stations, investment costs of pipeline, investment costs of stations, investment costs of operation, equivalent cost, which have been involved in distance natural gas pipeline proposals. According to relations of domination, indexes have been grouped to form relations of domination attribute hierarchy model with the basic idea of AHM (see Figure 1).

\section{B. Determining the weights}

Supposed $B$ is a criteria, $b_{1}, \quad b_{2}, \cdots, \quad b_{n}$ are $n$ elements, for criteria $\mathrm{B}$, comparing $b_{i}$ and $b_{j}(\mathrm{i} \neq \mathrm{j})$, and the relative importance of the criteria for $B$, which based on $b_{i}$ and $b_{j}$, denoted as $u_{i j}$ and $u_{j i}$. Meanwhile, in accordance with the attribute measurement requirements, $u_{i j}$ and $u_{j i}$ should meet:

$$
\begin{aligned}
& u_{i j} \geqslant 0, u_{j i} \geqslant 0, u_{i j}+u_{j i}=1, \mathrm{i} \neq \mathrm{j} \\
& u_{i j}=0, \mathrm{i}=\mathrm{j}, 1 \leqslant \mathrm{i} \leqslant \mathrm{n}, 1 \leqslant \mathrm{j} \leqslant \mathrm{n}
\end{aligned}
$$

$u_{i j}$, which meet (1), (2) is called relative attribute measure, its composition matrix $\left(u_{i j}\right)_{1 \leq i, j \leq n}$ is called attribute judgment matrix. Which determined by analytic hierarchy process, the conversion formula can be defined as formula (3), in which $1 \leq k \leq \mathrm{n}$, the value of $u_{i j}$ can be determined by the 1-9 ratio scale. So, the elements $u_{i}$ of relative attribute measure $u_{i j}$ based on the criteria $B$ can be calculated as follows: 


$$
u_{i j}=\left\{\begin{array}{cl}
\frac{k}{k+1}, & a_{i j}=k, i \neq j \\
\frac{1}{k+1}, & a_{i j}=\frac{1}{k}, \quad i \neq j \\
0, & a_{i j}=1, i=j
\end{array}\right.
$$

Attribute judgment matrix $\left(u_{i j}\right)_{1 \leq i, j \leq n}$ is consistency, and the characteristic roots of the matrix and eigenvectors needn't to be calculated, so did consistency. Where Attribute weights $W_{c}$ is calculated as follows:

$$
W_{c}=\left(W_{c}(1), W_{c}(2), \cdots ; W_{c}(n)\right)^{T}=\frac{2}{{ }_{n}(n-1)} \sum_{j=1}^{n} u_{i j}, \quad 1 \leq i \leq n(4)
$$

\section{COMPREHENSIVE ASSESSMENTS OF NATURAL GAS LONG DISTANCE GAS PIPELINE DESIGN}

Proposed a long distance gas pipelines across the board long $880 \mathrm{~km}$, the amount of design tasks is $9 \times 10^{8} \mathrm{~m}^{3} / \mathrm{a}$, the supply pressure of gas fields is $5.88 \mathrm{MPa}$, the natural gas allocation is 0.6 , the terminal pressure across the board require not less than $0.98 \mathrm{MPa}$. Natural gas pipeline designs are divided into several groups according to the difference of diameters, parameters which are related to be same with reference [1]. Choosing one of 12 kinds of representative program, the design values of specific parameters can be seen from table II. Then the program, which economically reasonable and technically feasible long can be determined by application of the AHM law.

\section{A. Attribute judgment matrix constructed at all levels, to determine the relative attribute weights}

The overall goal, which is long distance gas pipeline design comprehensive evaluation $(A)$, two factors in the guidelines layer involving engineering design effect $\left(B_{1}\right)$ and economic effects $\left(B_{2}\right)$ long gas pipeline construction and production process has the same importance according to the questionnaire survey carried out by the Group of Experts.

During long gas pipeline construction process, the cost is divided into two parts, which are investment costs of the pipeline construction and the establishment of the station investment, and the diameter of a direct impact on the size of the pipeline investment costs. Meanwhile, the construction number, not only affects the establishment of the station investment costs, but also affects the operation and management costs in the long run. Besides, the larger the diameter, the greater the pipeline investment in certain gas transmission capacity, but investment in gas compression stations will be reduced. As far as engineering design of rules layer effect $\left(B_{1}\right)$ concerned, the diameter and the number of compressor stations has significant importance compared with other design parameters because of their interaction and mutual restraint.

With the increase in the diameter, It can be found that construction cost of compressor stations and pipeline operating expenses showed a decreasing trend while daily maintenance of the pipeline, overhaul cost, depreciation charges would increase by correlation analysis of each evaluation index. In other words, equivalent costs of year would increase. Therefore, economic effects $\left(B_{2}\right)$ of the criteria level are closely related to pipeline investment costs, establishment of investment costs, operation and management costs. It can be concluded that equivalent costs of year has a significant importance compared with other economic indicators.

The Judgment matrix can be constructed by 1-9 importance scale method, and judgment matrix of AHM can be converted to corresponding measure judgment matrix by formula (3), then monolayer relative weights of each index is calculated by (4).

Namely, phase weight of $A$ according to $B_{1}, B_{2}$ is $W_{c 1}=$ $[0.5,0.5]^{T}$; phase weight of $B_{1}$ according to $C_{1}, C_{2}, \mathrm{C}_{3}, \mathrm{C}_{4}$, $\mathrm{C}_{5}$ is $W_{c 2}=[0.3,0.1333,0.1333,0.1333,0.3]^{T}$, phase weight of $B_{2}$ according to $C_{6}, C_{7}, C_{8}, C_{9}$ is $W_{c 3}=$ $[0.1875,0.1875,0.1875,0.4375]^{T}$.

Since design evaluation system of long gas pipeline is constituted by a hierarchy of multiple targets, it should be considered that relative importance of all the factors in the same level to the highest target layer in calculating comprehensive weight. Such as comprehensive weight of total goals to $C$ is $W_{c}=0.5 \times 0.153=0.0765$, and comprehensive weight of total goals to various indicators is $W_{c}=[0.15,0.067,0.067,0.067,0.15,0.0938,0.0938,0.0937,0.21$ $88]^{T}$. it can be easy found that equivalent cost, diameter, and compressor station number has a significant importance for the result of evaluation. Compared with other economic indicators by long distance gas pipeline design comprehensive evaluation of the relative weight value

\section{B. Comprehensive assessment of Reselected design programs}

Since reselected design programs of long gas pipeline involved 9 evaluation parameters dimensionless units vary widely, it can not be compared between them. It should be processed original number with no dimensionless ${ }^{[15]}$ in order to make the various pre-selected program comparable, for numerical design evaluation effect positive correlation parameters (such as delivery pressure), divided by the maximum value of this parameter directly; negative evaluation of the effect of numerical design parameters (such as diameter, first stop pressure ratio, the intermediate stations pressure ratio, the number of stations, pipeline investment costs, establishment of investment costs, operating investment costs, and equivalent to the cost), with the maximum value of the parameter minus the difference divided by the maximum of the individual parameters. Then a comprehensive evaluation of the long gas pipeline design, with different methods ${ }^{[1,3,8]}$ sorting of long gas pipeline design to compare the relative ranking of the results in Table I, which verifies AHM method better discriminated ability and practicality. 
TABLE I. THE RESULT OF COMPREHENSIVE ASSESSMENT OF NATURAL GAS PIPELINE DESIGN PROPOSAL

\begin{tabular}{|c|c|c|c|c|}
\hline Proposals & $\begin{array}{c}\text { AHM } \\
\text { method }\end{array}$ & $\begin{array}{c}\text { AHP } \\
\text { method }\end{array}$ & $\begin{array}{l}\text { Gray system } \\
\text { method }\end{array}$ & $\begin{array}{l}\text { Entropy } \\
\text { weight } \\
\text { coefficient } \\
\text { method }\end{array}$ \\
\hline 1 & 11 & 4 & 4 & 4 \\
\hline 2 & 1 & 3 & 1 & 3 \\
\hline 3 & 3 & 1 & 2 & 2 \\
\hline 4 & 5 & 9 & 8 & 6 \\
\hline 5 & 12 & 12 & 12 & 11 \\
\hline 6 & 6 & 9 & 10 & 9 \\
\hline 7 & 10 & 5 & 6 & 5 \\
\hline 8 & 2 & 2 & 3 & 1 \\
\hline 9 & 9 & 11 & 9 & 7 \\
\hline 10 & 4 & 6 & 5 & 8 \\
\hline 11 & 8 & 8 & 7 & 12 \\
\hline 12 & 7 & 7 & 11 & 10 \\
\hline
\end{tabular}

It can be seen from table 2 that the results of primary design scheme of long distance natural gas pipelines is ranked by the four methods (gray relative analysis method, AHP method, entropy weight coefficient method and AHM method ) all consider that the scheme 2, 8 and 3 are superior to the other design schemes, and both of the gray relative analysis method and AHM method consider that the scheme 2 is the best scheme. So the application of AHM method to evaluate the primary design scheme of long distance natural gas pipelines is not only reflecting the technical feasibility but also the optimality and economical efficiency of the design scheme in the project.

\section{CONCLUSIONS AND AWARENESS}

1) Nine parameters which included diameter, delivery pressure, pressure ratio of the first station, pressure ratios of intermediate stations, number of stations, investment costs of pipeline, investment costs of stations, investment costs of operation, equivalent cost, have been selected to evaluate design projects of the long distance natural gas pipeline based on AHM method. The results indicate that attribute AHM matches other methods well, such as AHP method, Gray system method, Entropy weight coefficient method, through Comparative analysis.

2) The calculation result of the example indicates that the AHM is a simple mathematic model, with easy operation. At the same time, the study provides a new method and technique for designers to select the technical feasible and economic reasonable design case, which has some theoretical and practical value. But it is worth noting that, the final weights of indexes based on AHM vary with values of time and experts, in which the determination of the importance of each index to a certain extent is still based on the experience of experts.

\section{REFERENCES}

[1] WANG Yuchun. Optimization in Oil and Gas Pipeline with Gray System Method [J]. Petroleum Planning \& Engineering, 1993,4(3):27-30.

[2] XIAO Fangchun. Fuzzy Matter-Element Optimum for Transportation Programs of Natural Gas Network Systems[J]. Oil-Gasfield Surface Engineering, 1996,16(3): 1-3.

[3] LIU Wu. Optimization of Long-distance Natural Gas Transportation Pipeline Design based on AHP Method [J]. Petroleum Planning \& Engineering, 2002,13(3):22-24.

[4] LIU Wu. Study on Optimization of Long-distance Natural Gas Transportation Pipeline Design [J]. Oil\&Gax Transporlation and Sponage,2004,22(3):21-24.

[5] [5] NIE Tingzhe and DUAN Changgui. Natural Gas Pipeline Systems Design Based on Fuzzy Decision [J]. Oil \& Gas Storage and Transportation ,2003,22(11): 28-31.

[6] WEN Tao,WANG Yuchun et al. Application of A Multi-valuation System for Gas Pipeline's EngineeringSchemes[J]. Oil \& Gas Storage and Transportation,2005, 24(8): 10-14.

[7] SU Xin,HUANG Kun, YANG Hua, et al. Application of Fuzzy Analysis of Hierachical Process(FAHP) in Optimizing Cross Pipeline Selection[J]. Journal of Oil and Gas Technology, 2005,27(6):801-802.

[8] SU Xin, XIE Ying, YUAN Zongming, et al. Optimization of Longdistance Natural Gas Transportation Pipeline Design Based on Entropy-Weight Coefficient Method [J]. Natural Gas Industry, 2007,27(4):112-114.

[9] LI Wanqing, MA Lihua, MENG Wenqing. Comprehensive evaluation model for the safety of fully mechanized mining face based on unascertainedmeasure and AHM [J]. Journal of China Coal Society, 2007,32(6): 614-616.

[10] CHENG Qiansheng. Analytic Hierarchy Process (AHP) and Attribute $\mathrm{H}$ ierarchical Model (AHM) [J]. Systems EngineeringTheory\&Practice, 1998,34(1) : 10-14 .

[11] CHENG Qiansheng. Analytic Hierarchy Process (AHP) and Attribute Hierarchical Model (AHM ) [J]. Systems EngineeringTheory\&Practice, 1997, (11) 25-28.

[12] CAI Huiping, CHENG Qiansheng. The Application of Attribute Hierarchical Model to Decision Making of Stock-Selection [J]. Mathematics in Practice and Theory, 2005,35(3):55-58.

[13] Ll Lianshui, WANG Guizhi, HUANG Xiao-rong et al. Meteorological Disaster Evaluation in AH M Research [J]. Journal of Applied Statisties and Management, 2011,30(2):201-205.

[14] CAI Zhenyu, LI Simin, REN Jian-hua, et al. Comprehensive Assessment of Urban Water Saving Level Based on AHM [J]. China Water\&Wastewater, 2006,22(7):54-56. 


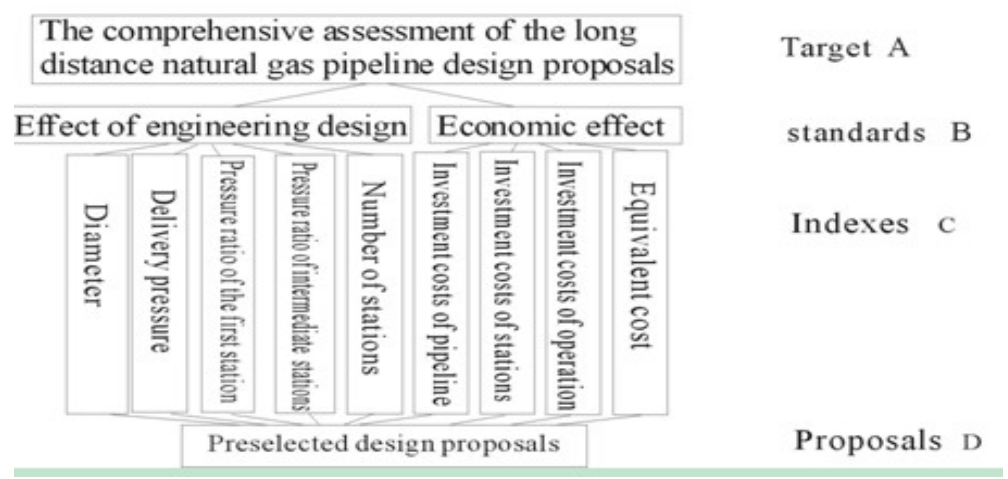

Figure 1. The hierarchical model of comprehensive assessment of the distance natural gas pipeline proposal

TABLE II. DATA AND INDICATORS OF AN NATURAL GAS PIPELINE IN TWELVE KINDS OF DESIGN

\begin{tabular}{|r|r|r|r|r|r|r|r|r|r|}
\hline Propposal & diameter & $\begin{array}{r}\text { delivery } \\
\text { pressure }\end{array}$ & $\begin{array}{r}\text { pressure } \\
\text { ratio of } \\
\text { the first } \\
\text { station }\end{array}$ & $\begin{array}{r}\text { pressure ratios } \\
\text { of intermediate } \\
\text { stations }\end{array}$ & $\begin{array}{r}\text { number of } \\
\text { stations }\end{array}$ & $\begin{array}{r}\text { investment costs of } \\
\text { pipeline }\end{array}$ & $\begin{array}{r}\text { investment } \\
\text { costs of } \\
\text { stations }\end{array}$ & $\begin{array}{r}\text { investment } \\
\text { costs of } \\
\text { operation }\end{array}$ & $\begin{array}{r}\text { equivalent } \\
\text { cost }\end{array}$ \\
\hline & $(\mathrm{mm})$ & $(\mathrm{Mpa})$ & & & & & \\
\hline 1 & 426.0 & 5.88 & 1.0 & 1.16 & 7 & 29815.33 & 3232.02 & 4626.45 & 37674.30 \\
\hline 2 & 529.0 & 5.88 & 1.0 & 1.16 & 1 & 39786.84 & 987.96 & 660.92 & 41435.45 \\
\hline 3 & 478.0 & 5.88 & 1.0 & 1.16 & 3 & 33172.33 & 1759.57 & 4049.54 & 38981.44 \\
\hline 4 & 630.0 & 3.60 & 1.0 & 1.17 & 1 & 42983.64 & 1016.92 & 712.57 & 44713.14 \\
\hline 5 & 529.0 & 3.60 & 1.0 & 1.17 & 6 & 36464.28 & 3070.59 & 6511.83 & 46046.71 \\
\hline 6 & 457.0 & 4.90 & 1.0 & 1.16 & 7 & 31816.82 & 3320.42 & 4782.64 & 39919.88 \\
\hline 7 & 529.0 & 4.90 & 1.0 & 1.16 & 2 & 36464.33 & 1387.00 & 1366.47 & 39217.75 \\
\hline 8 & 478.0 & 4.90 & 1.0 & 1.17 & 5 & 33172.33 & 2584.56 & 6864.96 & 42721.79 \\
\hline 9 & 478.0 & 7.35 & 1.25 & 1.16 & 2 & 38611.2 & 1525.53 & 1611.24 & 41747.97 \\
\hline 10 & 426.0 & 7.35 & 1.25 & 1.16 & 5 & 32477.37 & 2630.08 & 7125.74 & 42233.19 \\
\hline 12 & 529.0 & 7.35 & 1.25 & 1.0 & 1 & 42493.3 & 1166.3 & 1953.00 & 45612.60 \\
\hline
\end{tabular}

